\title{
Specific Affinity between Fibronectin and the Epidermolysis Bullosa Acquisita Antigen
}

David T. Woodley, Edward J. O'Keefe, John A. McDonald,“ Melinda J. Reese, Robert A. Briggaman, and W. Ray Gammon Department of Dermatology, University of North Carolina School of Medicine, Chapel Hill, North Carolina 27514; and *Department of Medicine, Washington University Medical Center, St. Louis, Missouri 63110

\begin{abstract}
Autoantibodies in the skin and sera of patients with epidermolysis bullosa acquisita bind to a large matrix molecule within the lamina densa region of skin basement membrane. At the site of these immune complexes, the epidermis separates from the dermis, which creates a subepidermal blister just below the lamina densa. The target molecule for the autoantibodies is in close apposition to fibronectin, a major extracellular matrix molecule that is abundant in the upper dermis of skin. In this report, we show specific affinity between fibronectin and the 290,000-D chain of the epidermolysis bullosa acquisita antigen, and that this affinity is mediated by the gelatin/collagen-binding domain of fibronectin $\left(M_{\mathrm{r}}=60,000\right)$. Since blistering in epidermolysis bullosa acquisita often occurs in the absence of clinical and histological inflammation, a direct interruption in the fibronectin-epidermolysis bullosa acquisita antigen bond may be involved in the pathogenesis of epidermal-dermal disadherence that occurs in this bullous disease.
\end{abstract}

\section{Introduction}

Epidermolysis bullosa acquisita (EBA) ${ }^{1}$ is a severe chronic subepidermal blistering disease of the skin in which autoantibodies form immune complexes just beneath the lamina densa compartment of the cutaneous basement membrane zone (BMZ) (1-5). At this sublamina densa site the epidermis separates from the dermis, which creates skin blisters. This process often occurs with minimal inflammation either clinically or histologically.

Anti-BMZ autoantibodies in the serum of patients or eluted from the $\mathrm{BMZ}$ of patients' skin bind to a large matrix molecule in the BMZ beneath stratified squamous epithelium of mammals, but not of birds, amphibians, or reptiles (6-8). This matrix molecule, the EBA antigen, is recognized as two chains $\left(M_{\mathrm{r}}\right.$ $=290,000$, and $\left.M_{\mathrm{r}}=145,000\right)$ in Western blots of human skin BMZ protein extracts reacted with patients' sera or a new monoclonal antibody, $\mathrm{H}_{3} \mathrm{a}(6-8)$. The 290,000-D chain is synthesized by human keratinocytes (9) and is composed of a $145-\mathrm{kD}$ collagen domain and a $145-\mathrm{kD}$ noncollagen domain that is rich in carbohydrate (10). These domains are covalently linked, and the $145-\mathrm{kD}$ noncollagen domain can be generated from the 290,000 D chain after treatment with collagenase.

Address correspondence and reprint requests to Dr. Woodley, Dept. of Dermatology, U. of North Carolina, 137 NCMH, Chapel Hill, NC 27514. 1987.

Received for publication 19 May 1986 and in revised form 28 January

1. Abbreviations used in this paper: BMZ, basement membrane zone; EBA, epidermolysis bullosa acquisita.

J. Clin. Invest.

(C) The American Society for Clinical Investigation, Inc.

$0021-9738 / 87 / 06 / 1826 / 05 \$ 1.00$

Volume 79, June 1987, 1826-1830
BMZ components such as laminin, heparan sulfate proteoglycan, and type IV collagen have specific affinities for one another that are thought to be necessary for the structure and function of this morphological unit (11-13). The EBA antigen, a major BMZ component, is in close apposition to fibronectin, another major matrix molecule that is highly biologically active and found throughout human skin dermis, but is concentrated in the papillary dermis and may be a component of some BMZs (14-17).

In this study, we report that the EBA antigen and fibronectin have specific affinity for each other and that this interaction is mediated via the collagen/gelatin-binding domain $\left(M_{\mathrm{r}}=60,000\right)$ of the fibronectin molecule. The affinity between the EBA antigen and fibronectin may play a role in physiologic epidermal-dermal adherence, and that the interference of this interaction could play a role in the blister formation that occurs in EBA.

\section{Methods}

Materials. All materials were obtained from Sigma Chemical Co., St. Louis, MO unless otherwise specified. Human immunoglobulin was obtained from Cooper Biomedical Cappel Worthington, Malvern, PA. Laminin routinely prepared from the Engelbreath Holm Swarm tumor (11) and commercially available laminin (BRL Laboratories, Bethesda, MD) were used. Fibronectin was prepared from human plasma as previously described $(15,16)$. Human placental extracts containing partially purified type I and V collagens were prepared according to Sage and Bornstein $(18,19)$.

Antibodies. The experimental antibodies used in this study include: (a) a murine monoclonal antibody, $\mathrm{H}_{3} \mathrm{a}$, to the EBA antigen which specifically stains the lamina densa-sublamina densa interface of the dermalepidermal junction in mammalian skin and labels both the 290- and 145-kD chains of the EBA antigen (7); (b) antibodies in the sera of four EBA patients that behave identically to the $\mathrm{H}_{3}$ a monoclonal (6); and (c) a goat affinity-purified antibody to human skin type I collagen (11).

The control antibodies used in this study include $(i)$ a murine monoclonal antibody to type IV collagen (20), (ii) four normal human sera (6), and (iii) two normal goat sera.

Western immunoblots. Proteins were extracted from human skin basement membrane (extract $A$ ), separated by sodium dodecyl sulfatepolyacrylamide gel electrophoresis (SDS-PAGE) on a 5\% slab gel, electrophoretically transferred to nitrocellulose, and reacted with experimental and control antibodies as previously described $(6,21)$.

It has been shown recently that the $290-\mathrm{kD}$ EBA band is composed of a 145-kD collagenase-sensitive domain and a $145-\mathrm{kD}$ collagenaseinsensitive domain which is rich in carbohydrate (10). Two new methods for preparing human skin basement membranes were devised to obtain extracts that only contained the $145-\mathrm{kD}$ collagenase-resistant, carbohydrate-rich domain or preferentially contained the $290-\mathrm{kD}$ species which consisted of both collagenase-sensitive and -insensitive domains. To preferentially extract the $290-\mathrm{kD}$ species, surgical specimens of human skin were obtained, washed with cold $1 \mathrm{M} \mathrm{NaCl}$ containing $0.010 \mathrm{M}$ cysteine and $0.005 \mathrm{M}$ ethylenediamine tetraacetate (EDTA; Fisher Scientific Co., Fair Lawn, NJ) (Wash Solution) for $1 \mathrm{~h}$ to inhibit human skin collagenase, which is localized within the papillary dermis. The skin was then sliced to $0.4 \mathrm{~mm}$ thickness with a Padgett keratotome and immediately incubated at $4^{\circ} \mathrm{C}$ in wash solution containing $0.001 \mathrm{M}$ 
phenylmethyl-sulfonyl fluoride (PMSF; Sigma Chemical Co.) with gentle agitation for $72 \mathrm{~h}$, at which time the epidermis was separated from the dermal basement membrane. The de-epidermized basement membrane was placed in liquid nitrogen and pulvarized into a fine powder and lyophilized. $4 \mathrm{~g}$ of dried powder was mixed with $80 \mathrm{ml}$ of $6 \mathrm{M}$ guanidine hydrochloride, $0.025 \mathrm{M}$ Tris- $\mathrm{HCl}, \mathrm{pH} 8.4,0.01 \mathrm{M}$ cysteine, $0.005 \mathrm{M}$ EDTA, 0.001 M PMSF (extraction solution), and extracted with gentle stirring at $4^{\circ} \mathrm{C}$ for $24 \mathrm{~h}$. The extract was centrifuged at $100,000 \mathrm{~g}$ for 1 $\mathrm{h}$ and the supernatant recovered. The supernatant was dialyzed against three changes, 2 liters each, of cold distilled water, lyophilized, and the dried material was weighed and labeled extract $B$.

$6 \mathrm{mg}$ of extract B was solubilized in $3 \mathrm{ml}$ of extraction solution adjusted to $\mathrm{pH} 7.2$ and lacking cysteine and EDTA, and dialyzed against three changes, $100 \mathrm{ml}$ each, of $0.025 \mathrm{M}$ Tris- $\mathrm{HCl}, 0.01 \mathrm{M}$ calcium acetate, $\mathrm{pH} 7.2,0.001 \mathrm{M}$ PMSF, $0.04 \mathrm{M} N$-ethylmaleimide, and $0.1 \%$ bovine serum albumin at $4^{\circ} \mathrm{C}$. Then, $30 \mathrm{U}$ of bacterial collagenase (Advanced Biofactures, Lynbrook, NY) was added and the solution incubated at $37^{\circ} \mathrm{C}$ for $48 \mathrm{~h}$. The solution was then cooled in an ice bath for $1 \mathrm{~h}$, made $0.005 \mathrm{M}$ EDTA, dialyzed against three changes, 2 liters each, of distilled water at $4^{\circ} \mathrm{C}$ using dialysis membranes with a 50,000 -D cutoff (Spectropor, Pittsburgh, PA), and lyophilized. This collagenase-treated preparation was labeled extract $C$. Proteins in extracts B and $C$ were handled identically to those in extract A: separated by SDS-PAGE and subjected to Western blot analysis with control and experimental antibodies as previously described $(6,10,18-21)$.

The blots were dried and an autoradiogram of the blots prepared with Kodak X-omat film according to Bonner and Laskey (22).

Western blots labeled with fibronectin. A variation of the Western blotting procedure was performed in which either laminin (11), whole fibronectin $(15,16)$, or purified fibronectin cell-binding and gelatinbinding domains $(23,24)$ were reacted with the skin $B M Z$ proteins rather than EBA antibodies. The binding of these matrix molecules to proteins separated and immobilized on the blot was detected by labeling each of the ligands with ${ }^{125} \mathrm{I}-\mathrm{NaI}$ (Amersham Corp., Arlington Heights, IL), according to Hunter and Greenwood (25), diluting the labeled proteins to 200,000 or $400,000 \mathrm{cpm} / \mathrm{ml}$ in $0.025 \mathrm{M}$ Tris-HCl, $\mathrm{pH} 7.4,0.2 \mathrm{M} \mathrm{NaCl}$, and incubating the solutions with lanes of proteins separated on nitrocellulose for $3 \mathrm{~h}$ at room temperature. The lanes were then washed, dried, and an autoradiogram prepared as with routine Western blots $(6,21)$.

In competition experiments, gelatin, bovine serum albumin, immunoglobulin, or laminin at concentrations between 100 and $400 \mu \mathrm{g} /$ $\mathrm{ml}$ were added (26) to the labeled ligand solutions before and during the incubation period to determine if the binding of fibronectin to EBA antigen could be inhibited. To determine the specificity for the fibronectinEBA antigen interaction, identical Western blots of laminin, bovine serum albumin, immunoglobulin, fibronectin, and extracts containing collagens $\mathrm{I}$ and $\mathrm{V}$ incubated with ${ }^{125} \mathrm{I}$-fibronectin were run in parallel with the BMZ protein extract. To determine directly which domain of fibronectin binds to the EBA antigen, a purified 60,000 -D gelatin/collagen-binding domain and a 160,000-140,000 cell-binding domain $(23,24)$ were labeled with ${ }^{125} \mathrm{I}-\mathrm{NaI}$ and reacted with immobilized proteins in the blots as outlined above.

Attempts were also made to block the fibronectin-EBA antigen interaction with EBA antibodies. Western blots were performed with extract $A$, and incubated with the $\mathrm{H}_{3}$ a monoclonal antibody, with EBA patient's sera $(n=2)$ diluted 1:25 ( $8 \times$ concentration of that used in routine blots), or with an IgG fraction $(20 \mathrm{mg} / \mathrm{ml})$ from one EBA patient who underwent a trial of plasmaphoresis. After incubating the blots for $3 \mathrm{~h}$ at room temperature, the blots were washed and incubated with ${ }^{125}$ I-fibronectin or a peroxidase-labeled second antibody for an additional $3 \mathrm{~h}$ at room temperature. The blots were then processed for autoradiography as above or developed with 4-chloro-1-naphthol to detect membrane bound antibody by standard methods (21).

\section{Results}

Antibodies in the sera of EBA patients and the $\mathrm{H}_{3}$ a monoclonal antibody bound to the 290,000 - and 145,000-D chains of the
EBA antigen in Western blots of the skin BMZ proteins in extract $A$ as previously described $(6,7)$ (lanes 1 and 3 , Fig. 1). The other multiple bands seen on identical Commassie Blue-stained gels of the BMZ extract (lane 6, Fig. 1) remained unlabeled (Fig. 1). To determine if fibronectin had affinity for any of the bands in the BMZ extract, ${ }^{125}$ I-fibronectin was incubated with Western blots of the extract and the subsequent labeling compared with specific EBA antibodies. The labeled soluble fibronectin incubated on the nitrocellulose sheets of immobilized BMZ proteins, bound to the same 290-kD band as the EBA antibodies (compare lanes 1 and 2, Fig. 1). When extract $A$ was used in the blots, some labeling of the 145-kD EBA band was also apparent just above the alpha chains of type I collagen. ${ }^{125}$ I-Fibronectin also bound to contaminating type I collagen bands in the BMZ extract as expected (26-29) in addition to the EBA antigen chains (Fig. 1, lane 2). All of the other bands in the extract remained unlabeled except for one: a protein band of $125,000 \mathrm{kD}$ that is uncharacterized. In contrast to fibronectin, ${ }^{125} \mathrm{I}$-laminin (another large sulfated matrix glycoprotein that is not juxtaposed to the EBA antigen in vivo) did not bind to the EBA antigen or collagen bands in the blot at either a 200,000 - or $400,000-\mathrm{cpm} / \mathrm{ml}$ concentration (Fig. 1, lanes 4 and 5).

The Coomassie Blue-stained SDS-polyacrylamide gels and the Western blots with labeled fibronectin suggested that type I collagen bands were a major contaminant of the skin BMZ extract. To examine this directly, Western blots of the extract were reacted with antibodies to type I collagen (11) (Fig. 2, lane 3). An affinity-purified goat anti-type I collagen antibody (11) labeled the alpha $\left(M_{\mathrm{r}}=118 \mathrm{kD}\right)$ and beta $\left(M_{\mathrm{r}}=215 \mathrm{kD}\right)$ type I collagen chains which are major proteins within the BMZ extract (Fig. 2). The presence of type I collagen within the BMZ extract was helpful as a positive control for fibronectin binding experiments, since fibronectin has high affinity for collagens $(11,14$, 26-29). Treatment of the BMZ extract with collagenase under highly stringent conditions degraded the $290-\mathrm{kD}$ EBA antigen chain (lane 2, Fig. 2) and type I collagen (lane 4, Fig. 2) in the extract, making them unavailable for labeling with their respective antibodies, and generated the $145-\mathrm{kD}$ collagenase-resistant portion of the EBA antigen that remained labeled by EBA antigen antibodies (Fig. 2, lane 2). Extracting the EBA antigen in the presence of irreversible (cysteine) and reversible (EDTA) collagenase inhibitors (extract $B$ ) inhibits the generation of the 145$\mathrm{kD}$ minor band (compare extract $\mathrm{A}$ in Fig. 1 , lane 1 with extract $B$ in Fig. 2, lane 1). The addition of exogenous collagenase to extract $B$ degrades the collagenase-sensitive portion of the EBA antigen and leaves a $145-\mathrm{kD}$ collagenase-insensitive domain (Fig. 2 , lane 2). This would suggest that the $290-\mathrm{kD}$ band is composed

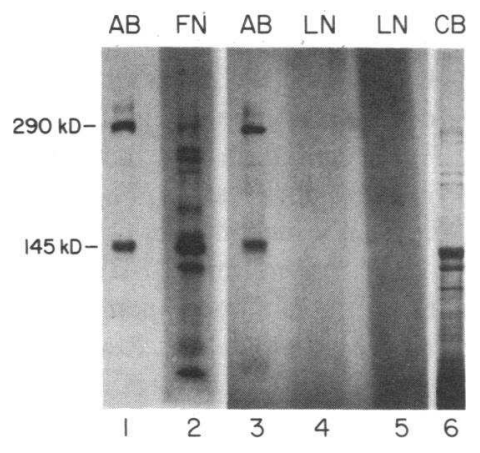

Figure 1. Western blot of skin BMZ extract. It was labeled with a monoclonal antibody (AB) to the EBA antigen (lanes $l$ and 3 ), ${ }^{125} \mathrm{I}$ labeled fibronectin (FN) at $200,000 \mathrm{cpm} / \mathrm{ml}$ (lane 2 ), or ${ }^{125}$ I-labeled laminin (LN) at $200,000 \mathrm{cpm} / \mathrm{ml}$ (lane 4) and $400,000 \mathrm{cpm} / \mathrm{ml}$ (lane 5). Lane 6 is a Coomassie Blue (CB)-stained SDSpolyacrylamide gel of the basement membrane extract. 


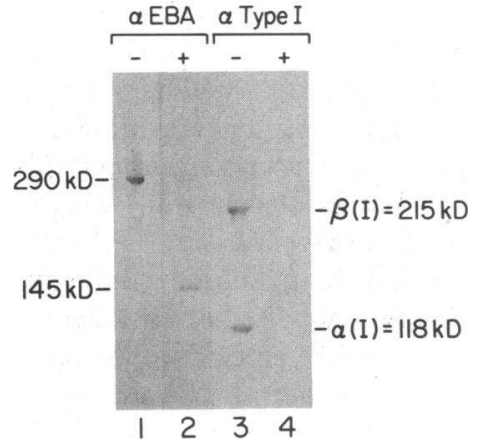

Figure 2. Western blot of skin basement membrane proteins. They were extracted in the presence of collagenase inhibitors (extract B) and incubated with inactive boiled collagenase (lanes 1 and 3 ) or active collagenase (lanes 2 and 4 ) and labeled with antibodies to the EBA antigen (lanes 1 and 2) or type I collagen (lanes 3 and 4). In the presence of collagenase inhibi-

tors, much less of the 145-kD EBA antigen band is seen in the extract (compare lane 1 of this figure with lanes 1 and 3 of Fig. 1). In collagenase-treated extracts, anti-EBA antigen antibodies no longer label the 290-kD band, while the 145-kD band becomes prominent (lane 2), and antibodies to type I collagen no longer label the contaminating type I collagen in the extract (compare lanes 3 and 4 ). Note that the $145-\mathrm{kD}$ band in lane 2 is distinct from the contaminating collagen bands labeled in lane 3 . The molecular weights of all of the bands are calculated from commercially available high molecular weight markers (Bio-Rad Laboratories, Richmond, CA). Collagens are known to run anomalously high in SDS-polyacrylamide gels. When the labeled bands in lane 3 were calculated against purified collagen standards (gift from Dr. Gerald Mechanic, University of North Carolina School of Dentistry), they have an $M_{\mathrm{r}}=95,000$, and an $M_{\mathrm{r}}=195,000$.

of two equal-sized 145-kD components: one of which is sensitive and the other which is insensitive to collagenase (10). EBA antigen, biosynthetically derived in tissue culture, demonstrates only one single $290-\mathrm{kD}$ band and no $145-\mathrm{kD}$ species $(9,30,31)$. This suggests that the $290-\mathrm{kD}$ band is the native molecule, while the $145-\mathrm{kD}$ band seen in tissue extracts represents a degradation product from the $290-\mathrm{kD}$ molecule $(9,30,31)$. Moreover, this experiment shows without a doubt that the $145-\mathrm{kD}$ collagenaseresistant domain is distinct from the type I collagen chains contaminating the BMZ extract.

Proteins, including the $145-\mathrm{kD}$ band, in the collagenasetreated preparation, extract $C$, failed to label with ${ }^{125}$ I-fibronectin in Western blots (data not shown). There is some labeling, however, of the $145-\mathrm{kD}$ band by fibronectin in extract A (lane 2, Fig. 1). One interpretation of this is that there is incomplete collagen degradation in extract $A$, and the observed $145-\mathrm{kD}$ species contains enough collagen to label with fibronectin unless exogenous collagenase is added. Alternatively, it could be argued that the collagenase treatment alters the extract and inhibits fibronectin binding by some other means not involving collagen at all.

To determine the specificity of fibronectin binding to collagen and the EBA antigen chains, the labeled fibronectin was reacted in parallel Western blots with albumin, laminin, immunoglobulin, fibronectin itself, and extracts containing type I and V collagen. As seen in Fig. 3, the fibronectin readily binds to type I collagen and the EBA antigen chains in the BMZ extract (lanes 1 and 2, Fig. 3) as well as the collagen $\mathrm{V}$ (lane 7, Fig. 3), but fails to label laminin (lane 3, Fig. 3). Albumin and immunoglobulin also failed to bind fibronectin (lanes 4 and 5, Fig. 3) as previously reported (27-29). Soluble fibronectin does not bind to fibronectin immobilized on a Sepharose column (27-29). We were surprised to find that labeled fibronectin bound somewhat to the fibronectin immobilized on the nitrocellulose. Recently, however, a "self aggregation" domain on the fibronectin molecule has been demonstrated (32-34).
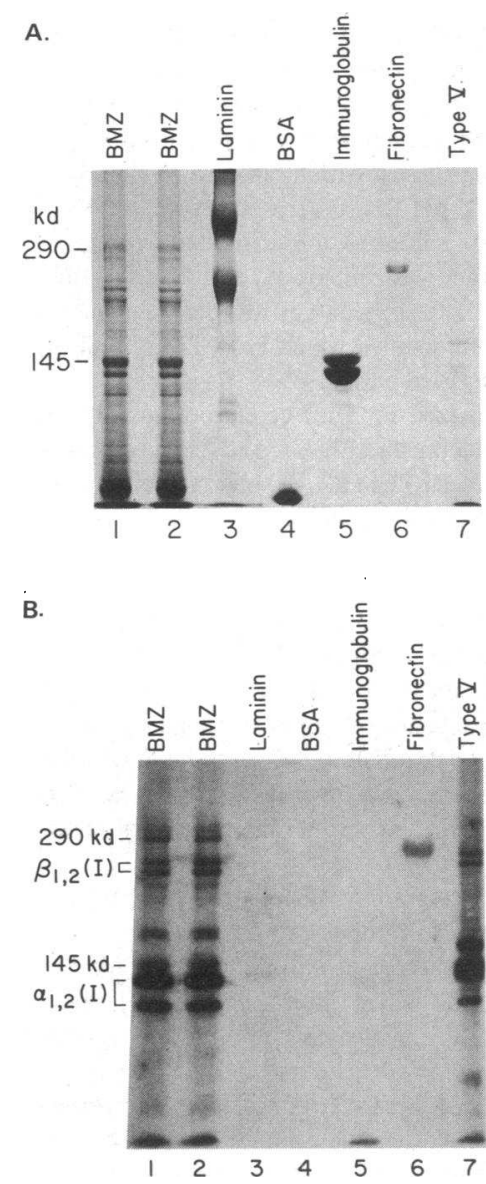

Figure 3. (A) Coomassie Blue-stained gel of the BMZ extract (lanes 1 and 2). Other molecules shown include laminin (lane 3), bovine serum albumin (lane 4), immunoglobulin (lane 5), fibronectin (lane 6), and type $\mathrm{V}$ collagen (lane 7). $(B)$ Western blot of the proteins in $A$ labeled with ${ }^{125} \mathrm{I}$ fibronectin. The fibronectin $\mathrm{kD}$ EBA antigen bands and extract (lanes 1 and 2). It also binds to type $\mathrm{V}$ collagen (lane 7), but fails to bind laminin, bovine serum albumin, or immunoglobulin (lanes 3-5). It does appear to bind to fibronectin immobilized on the blot (lane 6). binds to the 290- and 145type I collagen in the BMZ

To examine the possibility that fibronectin binding to the EBA antigen chains is mediated by the gelatin/collagen-binding domain of fibronectin, labeled fibronectin incubations were carried out in the presence of 0,100 , or $200 \mu \mathrm{g}$ of gelatin or unrelated proteins such as bovine serum albumin, immunoglobulins, and laminin. As seen in Fig. $4 \mathrm{~A}$, the addition of gelatin inhibits the fibronectin binding to the EBA chains in a concentration-dependent manner. The specificity for this inhibition is seen in Fig. $4 B$, in which the addition of gelatin (lane 5, Fig. $4 B$ ) inhibits the binding of fibronectin to the EBA chains and type I collagen, while the addition of laminin, albumin, or immunoglobulin does not.

To determine directly if the gelatin/collagen domain of the fibronectin molecule mediated the interaction between EBA and fibronectin, purified fibronectin fragments $(23,24)$ were labeled and incubated with Western blots of the BMZ extract. Fig. 5 shows ${ }^{125}$ I-labeled whole fibronectin compared with the gelatin and cell-binding fragments by SDS-PAGE. In Fig. 6 a comparison of whole fibronectin, the $60-\mathrm{kD}$ fibronectin gelatin-binding domain, and the $140-160-\mathrm{kD}$ fibronectin cell-binding domain reacted with the $\mathrm{BMZ}$ proteins shows directly that the fibronectin gelatin-binding domain interacts with the EBA antigen chains. The cell-binding domain of fibronectin does not react with either collagens or the EBA antigen chains in the extracts.

\section{Discussion}

EBA is a severe blistering disease of the skin in which the epidermis separates from the dermis just below the lamina densa compartment of the cutaneous $\mathrm{BMZ}$, where autoantibodies are 

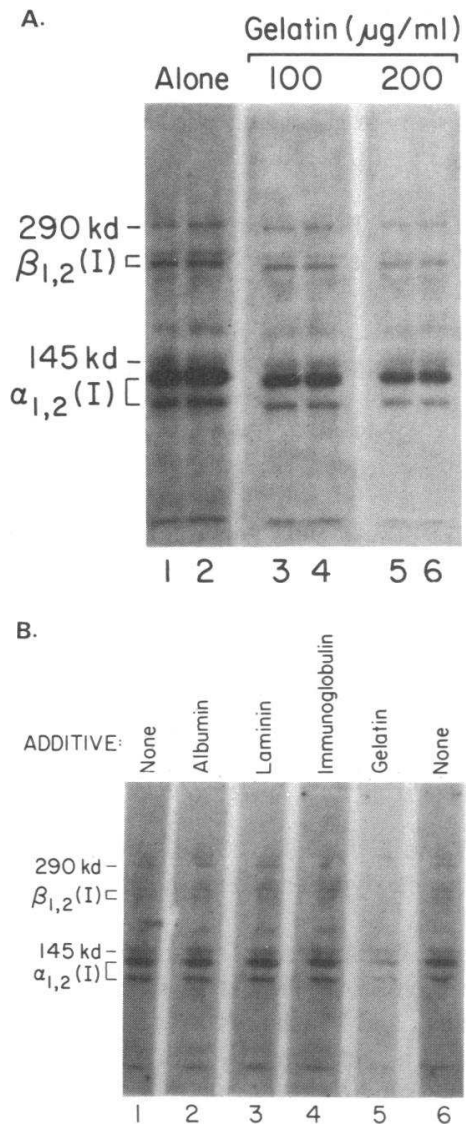

Figure 4. (A) Western blot of the BMZ extract. It was incubated with ${ }^{125}$ I-labeled fibronectin alone (lanes 1 and 2) or in the presence of $100 \mu \mathrm{g} / \mathrm{ml}$ (lanes 3 and 4) or $200 \mu \mathrm{g} / \mathrm{ml}$ (lanes 5 and 6) of gelatin. The presence of gelatin inhibits the fibronectin labeling of the EBA antigen bands and type I collagen bands in the extract. $(B)$ Western blot of the BMZ extract (lanes 16). It was incubated with ${ }^{125}$ I-labeled fibronectin alone (lanes 1 and 6) or in the presence of $300 \mu \mathrm{g} / \mathrm{ml}$ albumin (lanes 2), laminin (lane 3), immunoglobulin (lane 4, or gelatin (lane 5). The presence of gelatin inhibits the fibronectin labeling of the 290- and 145-kD EBA antigen bands and type I collagen chains in the extract.

lodged (2-6). This often occurs in the setting of little or no clinical and histological evidence of inflammation (1). It is possible that the apparent abrogation of epidermal-dermal adherence may occur by the direct effects of immune complexes on resident extracellular matrix molecules and interactions between them. Large matrix molecules within the BMZ have specific affinities for each other and bind to one another at specific domains on the molecules $(11-14,28,29,33)$. It is thought that these molecular affinities play a role in the functional and structural integrity of the BMZ. Immunoelectron microscopy with highly specific antibodies have demonstrated that fibronectin and the

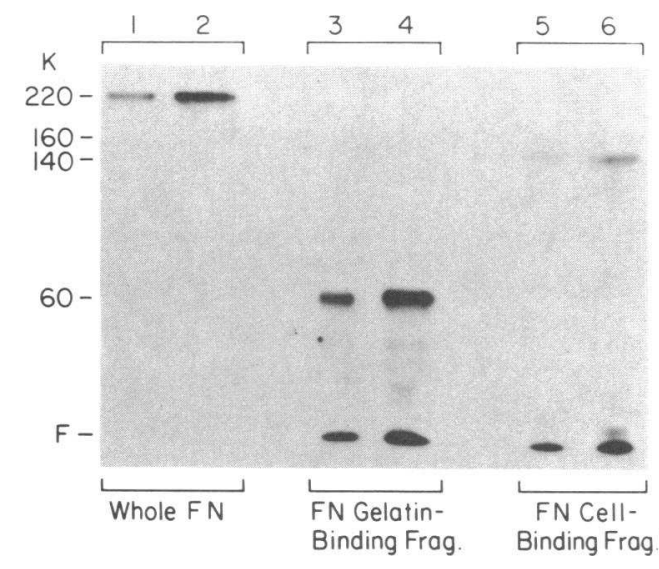

Figure 5. 5\% SDS-polyacrylamide gel of ${ }^{125}$ I-labeled whole fibronectin (FN) (lanes 1 and 2, a 60-kD fibronectin gelatin-binding fragment (Frag.) (lanes 3 and 4), and a 140-160 kD cell binding fragment (lanes 5 and 6$)$.
Figure 6. Western blot of the BMZ extract. It was incubated with ${ }^{125} \mathrm{I}$-labeled whole fibronectin (FN) (lane $l$ ) at a $200,000 \mathrm{cpm} / \mathrm{ml}$ dilution and ${ }^{125} \mathrm{I}$-labeled fibronectin gelatin/collagen-binding fragment (Frag.) (lane 2) and ${ }^{125}$ I-labeled cellbinding fragment (lane 3) at a 400,000 $\mathrm{cpm} / \mathrm{ml}$ dilution. Approximately twice the number of radioactive counts with the gelatin/collagen-binding fragment were needed to give equivalent binding to the EBA antigen bands as whole fibronectin. This is because the fragment represents monomeric fibronectin, while the whole fibronectin is dimeric. The ${ }^{125} \mathrm{I}$-labeled cell-binding fragment of fibronectin did not label any of the protein bands in the BMZ extracts (lane 3).

EBA antigen chains are in close apposition within the cutaneous $\operatorname{BMZ}(6,8)$. In this report, we show that these two matrix components have specific affinity for each other and that this interaction is mediated by the gelatin/collagen-binding domain on the fibronectin molecule.

Although we were unable to block the fibronectin-EBA antigen interaction with EBA antibodies in our in vitro Western blot assay, it is possible that this interaction is perturbed in vivo when high concentrations of EBA autoantibodies complex with antigen within the BMZ. It must be emphasized that in our in vitro system we are using denatured EBA antigen that is isolated from other matrix components. It cannot be assumed that the nature of the antigen-antibody complexes and the concentration of bound antibody in vitro is identical to that found in diseased skin. Nevertheless, the fact that the EBA antigen and fibronectin are closely apposed in skin and have specific affinity for each other in vitro would suggest that this interaction may play a role in maintaining normal dermal-epidermal adherence, and that abrogation of this interaction may be relevant to the pathogenesis of EBA, a bullous disease characterized by a paucity of inflammation.

\section{Acknowledgments}

We thank Ms. Donna Foushee for the preparation of this manuscript. We thank Dr. John Scheinman, Duke University, Durham, NC, for antibodies to type IV collagen.

This work was supported by grants AM-33625 and AM-25871, and Research Career Development Award AM-01540, from National Institutes of Health.

\section{References}

1. Roenigk, H. H., Jr., J. G. Ryan, and W. F. Bergfeld. 1971. Epidermolysis bullosa acquisita: report of three cases and review of all published cases. Arch. Dermatol. 103:1-10.

2. Nieboer, C., D. M. Boorsma, M. J. Woerdeman, and G. L. Kalsbeek. 1980. Epidermolysis bullosa acquisita: immunofluorescence, electron microscopic studies in four patients. Br. J. Dermatol. 102:383-392.

3. Roenigk, H. H., Jr., and R. W. Pearson. 1981. Epidermolysis bullosa acquisita. Arch. Dermatol. 117:383.

4. Yaoita, H., R. A. Briggaman, T. J. Lawley, T. T. Provost, and S. I. Katz. 1981. Epidermolysis bullosa acquisita: ultrastructural and immunological studies. J. Invest. Dermatol. 76:288-292.

5. Gibbs, R. B., and H. R. Minus. 1975. Epidermolysis bullosa acquisita with electron microscopical studies. Arch. Dermatol. 111:215220. 
6. Woodley, D. T., R. A. Briggaman, E. J. O'Keefe, A. O. Inman, L. L. Queen, and W. R. Gammon. 1984. Identification of the epidermolysis bullosa acquisita antigen-a normal component of human skin basement membrane. N. Engl. J. Med. 310:1007-1013.

7. Paller, A. S., L. L. Queen, D. T. Woodley, W. R. Gammon, E. J. O'Keefe, and R. A. Briggaman. 1985. A mouse monoclonal antibody against a newly discovered basement membrane component, the epidermolysis bullosa acquisita antigen. J. Invest. Dermatol. 84:215-217.

8. Paller, A. S., L. L. Queen, D. T. Woodley, A. T. Lane, W. R. Gammon, and R. A. Briggaman. 1986. Organ-specific, phylogenetic and ontogenetic distribution of the epidermolysis bullosa acquisita antigen. J. Invest. Dermatol. 86:376-379.

9. Woodley, D. T., R. A. Briggaman, W. R. Gammon, and E. J. O'Keefe. 1985. Epidermolysis bullosa acquisita antigen is synthesized by human keratinocytes cultured in serum-free medium. Biochem. Biophys. Res. Commun. 130:1267-1272.

10. Woodley, D. T., E. J. O'Keefe, M. J. Reese, G. H. Mechanic, R. A. Briggaman, and W. R. Gammon. 1986. The epidermolysis bullosa acquisita antigen, a major component of the cutaneous basement membrane is a glycoprotein with collagenous domains. J. Invest. Dermatol. 86:668-672.

11. Woodley, D. T., C. N. Rao, J. R. Hassell, L. A. Liotta, G. R. Martin, and K. H. Kleinman. 1983. Interactions of basement membrane components. Biochim. Biophys. Acta. 761:278-283.

12. Yurchenco, P. D., and H. Furthmayr. 1984. Self assembly of basement membrane collagen. Biochemistry. 23:1839-1850.

13. Terranova, V. P., C. N. Rao, T. Kalebic, I. M. Margulies, and L. A. Liotta. 1983. Laminin receptor on human breast carcinoma cells. Proc. Natl. Acad. Sci. USA. 80:444-448.

14. Yamada, K. M. 1982. Fibronectin and other structural proteins. In Cell Biology of the Extracellular Matrix. E. D. Hay, editor, Plenum Press, New York. 95-114.

15. O'Keefe, E. J., D. T. Woodley, G. Castillo, N. Russell, and R. E. Payne, Jr. 1984. Production of soluble and cell-associated fibronectin by cultured keratinocytes. J. Invest. Dermatol. 82:150-155.

16. O'Keefe, E. J., R. E. Payne, Jr., N. Russell, and D. T. Woodley. 1985. Spreading and enhanced motility of human keratinocytes on fibronectin. J. Invest. Dermatol. 85:125-130.

17. Boselli, J. M., E. J. Macarak, and C. C. Clark. 1981. Fibronectin: its relationship to basement membranes. Collagen Relat. Res. 1:391404.

18. Sage, H., and P. Bornstein. 1979. Characterization of a novel collagen chain in human placenta and its relation to $\mathrm{AB}$ collagen. Biochemistry. 18:3815-3821.

19. Woodley, D. T., V. J. Scheidt, M. J. Reese, A. A. Paller, T. O. Manning, T. Yoshiike, and R. A. Briggaman. 1987. Localization of the alpha $3(\mathrm{~V})$ chain of type V collagen in human skin. J. Invest. Dermatol. $88: 247-253$

20. Scheinman, J. I., and C. Tsai. 1984. Monoclonal antibody to type IV collagen with selective basement membrane localization. Lab. Invest. 50:101-112.

21. Towbin, H. T., T. Staehelin, and J. Gordon. 1979. Electrophoretic transfer of proteins from polyacrylamide gels to nitrocellulose sheets: procedures and some applications. Proc. Natl. Acad. Sci. USA. 76:43504354.

22. Bonner, W. M., and R. A. Laskey. 1974. A film detection method for tritium-labelled proteins and nuclei acids in polyacrylamide gels. Eur. J. Biochem. 46:83-88.

23. Ingham, K. C., S. A. Brew, T. J. Broekelmann, and J. A. McDonald. 1984. Thermal stability of human plasma of human plasma fibronectin and its constituent domains. J. Biol. Chem. 259:1901-1907.

24. McDonald, J. A., and D. A. Kelly. 1980. Degradation of fibronectin by human leukocyte elastase: release of biologically active fragments. J. Biol. Chem. 225:8848-8858.

25. Hunter, W. M., and F. C. Greenwood. 1962. Preparation of iodine131 labeled human growth hormone of high specific activity. Nature (Lond.). 194:495-496.

26. Bell, M. L., and E. Engvall. 1982. The specific detection of collagenous proteins after electrophoresis using enzyme-conjugated collagenbinding fibronectin fragments. Anal. Biochem. 123:329-335.

27. Ruoslahti, E., E. Engvall, and E. G. Hayman. 1981. Fibronectin: current concepts of its structure and function. Collagen Relat. Res. 1: 95-128.

28. Engvall, E., E. Ruoslahti, and E. J. Miller. 1978. Affinity of fibronectin to collagen of different genetic types and to fibrinogen. J. Exp. Med. 147:1584-1595.

29. Ruoslahti, E., and E. Engvall. Complexing of fibronectin glycosaminoglycans and collagen. 1980. Biochim. Biophys. Acta. 631:350-358.

30. Stanley, J. R., N. Rubinstein, and V. Klaus-Kovtun. 1985. Epidermolysis bullosa acquisita antigen is synthesized by both human keratinocytes and human dermal fibroblasts. J. Invest. Dermatol. 85:542-545.

31. Woodley, D. T., R. A. Briggaman, W. R. Gammon, R. J. Falk, M. J. Reese, R. S. Tomsick, and E. J. O'Keefe. 1986. Epidermolysis bullosa acquisita antigen, a major cutaneous basement membrane component synthesized by human dermal fibroblasts and other cutaneous tissues. J. Invest. Dermatol. 87:227-231.

32. Homandberg, G. A., D. B. Evans, J. Kramer, and J. W. Erickson. 1985. Interaction between fluorescence-labelled fibronectin fragments studied by gel high-performance liquid chromatography. J. Chromatogr. 327:343-349.

33. McDonald, J. A., D. G. Kelley, and T. J. Broekelmann. 1982. Role of fibronectin in collagen deposition: FAB to the gelatin-binding domain of fibronectin inhibits both fibronectin and collagen organization in fibroblast extracellular matrix. J. Cell. Biol. 92:485-492.

34. Ehrismann, R., D. E. Roth, H. M. Eppenburger, and D. C. Turner. 1982. Arrangement of attachment-promoting, self-association, and heparin-binding sites in horse serum fibronectin. J. Biol. Chem. 257:73817387. 